\title{
La tenencia de la tierra en el asentamiento humano Sagrada Familia ${ }^{1}$
}

\section{Mirva Aranda, Patricia Flórez, Carmen Gutiérrez, Vanessa LuYo y Flor de María VALDEZ}

\section{Introducción}

El grupo social elegido es el asentamiento humano Sagrada Familia. El trabajo pretende analizar el problema de la tenencia de la tierra y su particular relevancia no sólo por los efectos concretos que causa en la ecología, sino además por su repercusión en la organización del grupo social.

Las razones que nos llevaron a elegir el asentamiento humano como grupo de estudio fueron las de encontrar en él una compleja y variada gama de relaciones humanas, $y$ porque a pesar de su continua referencia diaria muy poco es lo que en realidad cada uno de nosotros había podido palpar en forma directa.

Otro de los motivos que nos llevó a la elección de este grupo social fue considerar que es en él donde se puede ver con más claridad las diferencias con el Derecho oficial; ello por existir respuestas espontáneas e inmediatas del pueblo frente a la necesidad, respuestas que pretenden salvar las deficiencias y los vacíos de un sistema que tal vez no les alcanza.

Realizamos distintos trabajos de campo, pero la característica de este pueblo que de inmediato llamó nuestra atención fue el hecho de encontrarse en una zona ecológica: los Pantanos de Villa.

El asentamiento humano se formó producto de una invasión sobre la zona pantanosa y sobre un sector de chacras, zona que luego fue rellenada hasta tres metros de altura, ocasionando con ello un desplazamiento de los pantanos.

Este trabajo ocupó el primer puesto en la categoría "A» del I Concurso de Investigación sobre Derecho y Realidad convocado en setiembre de 1995 por nuestra facultad, para promover la investigación entre los alumnos. 
El problema de la tenencia de la tierra en este asentamiento humano nos hacía vislumbrar características peculiares, y a pesar de que en un principio mientras más profundizábamos en nuestras entrevistas más nos desconcertábamos y confundíamos, al final creemos que podemos decir con satisfacción que no nos equivocamos al escoger este grupo social y el tema en particular.

Además podíamos vislumbrar un conflicto jurídico respecto a la propiedad de la tierra, un conflicto entre la realidad de la ocupación de esas tierras y la zona ecológica que se supone el Derecho debe tutelar.

Pretendemos con este trabajo hacer un pequeño aporte para que se tome conciencia de que estos grupos llamados «marginales" pueden ser reflejo concreto de lo que sucede en muchas partes del país, pues los asentamientos humanos involucran un sector bastante importante de la sociedad.

\section{El asentamiento humano Sagrada Familia}

\subsection{Ubicación geográfica}

\subsubsection{Ubicación}

El asentamiento humano Sagrada Familia se encuentra ubicado en el kilómetro 18,5 de la antigua carretera Panamericana Sur, en el distrito de Chorrillos. Ocupa una extensión aproximada de 42000 metros cuadrados.

\subsubsection{Relación con la zona ecológica de los Pantanos de Villa}

Una de las características peculiares del asentamiento humano en estudio es que se encuentra asentado en una parte de la zona ecológica de los Pantanos de Villa, característica que influirá decisivamente en su organización, como veremos más adelante.

Los Pantanos de Villa constituyen el único foco ecológico que queda al sur de Lima, donde diversidad de aves llegan migrando de lugares lejanos para poder reposar luego de un largo viaje. Sin embargo, cada vez lo encuentran más disminuido debido a los rellenos hechos por parte de los pobladores y de terceros dueños de áreas que antes no se encontraban dentro de la zona ecológica -circunstancia que luego detallaremos-, producto de la invasión.

El asentamiento humano Sagrada Familia invadió un sector principal de los Pantanos en el año 1987. Sin embargo, dicha zona fue decla- 
rada reserva posteriormente, en el año 1989, según resolución ministerial 00144. De allí el conflicto entre el Estado, los pobladores y un tercero, quienes se sienten dueños.

\subsection{Antecedentes}

\subsubsection{Circunstancias de la invasión}

Hace aproximadamente ocho años los Pantanos de Villa colindaban con algunas urbanizaciones hacia el noroeste y con campos de cultivos en el noreste.

Dichos campos de cultivos (maíz y camote), propiedad del Sr. Gran, abarcaban desde el final de los Pantanos, a la altura de la primera zona de Las Delicias, hasta lo que se conoce como «la Curva».

Todos estos terrenos de cultivo, más una porción de los propios Pantanos (lo que ahora es Sagrada Familia), fueron invadidos el mismo día, el 18 de enero de 1987, en horas de la noche (como suelen suceder las invasiones).

La invasión fue iniciativa de unos cuantos, a quienes se acoplaron todos los que se enteraron. No fue una organización de grupos vinculados por algún motivo especial; simplemente se dio la oportunidad y participaron todos los que pudieron.

$\mathrm{Al}$ respecto nos cuenta el Sr. Velásquez, subsecretario general de Sagrada Familia:

"fue una casualidad, porque el que le habla, yo, me iba a mi trabajo a las nueve de la mañana y vi la invasión de la gente; agarraban sus esteras, algunos con sus palitos, con sus piedras y empezaron a ubicarse desordenadamente, y luego ahí intervení; también me ubiqué".

Respecto a la razón de haberse ubicado en una zona tan difícil, los pobladores señalaron que en la invasión no se escoge; simplemente se da la oportunidad de un sitio apropiado y hay que aprovecharla, y el principal motivo que los lleva a ello es la necesidad de tener un sitio donde vivir.

\subsubsection{Consecuencias de la invasión en la ecología}

Dado que el terreno invadido constituía parte de la zona ecológica de los Pantanos de Villa, la invasión generó graves efectos en el sistema ecológico de esa zona. 
En el lugar en que se ubicó Sagrada Familia había un "ojo de agua» que surtía toda la zona que era pantanosa, cubierta con una densa vegetación.

$\mathrm{Al}$ ser cubierto este terreno con el relleno, el agua -literalmente- se trasladó al otro lado de la pista (antigua Panamericana Sur), a la parte constituida por terrenos de propiedad privada.

Esto produjo un fenómeno especial, por el cual lo que antes era pantano fue rellenado y ocupado por Sagrada Familia y una parte no rellenada quedó seca, sin agua, sin vegetación. La zona del otro lado de la pista, que era de propiedad privada, se inundó; incluso algunas casas quedaron en medio del agua.

Los pobladores de Sagrada Familia son conscientes de que se encuentran en una zona ecológica, como pudimos comprobar en nuestras entrevistas, pero intentan justificarse diciendo que a veces la necesidad obliga.

El Sr. Velásquez señala, como para reivindicarse, lo siguiente:

«nosotros somos como parte, más claro, como los guardianes [de los pantanos]; ya no aceptamos más invasiones y más allá lo vamos a cuidar. Ése es el acuerdo que hemos entrado, porque qué parecería que vamos a seguir aceptando a los invasores; nos perjudicaría a nosotros».

El acuerdo del que habla el dirigente supuestamente es con el propio INRENA (Instituto de Recursos Naturales); sin embargo no nos quiso dar mayor detalle al respecto.

Los pobladores eran conscientes de que invadían una zona ecológica; sin embargo, al ser confrontado esto con una necesidad básica como la vivienda se ven forzados a pasar eso por alto.

Por otro lado, esa misma necesidad fundamental es la que los lleva a rechazar a nuevos invasores, quienes los perjudicarían. A pesar de que estos nuevos invasores tienen la misma necesidad, sin embargo esto se ve confrontado ahora con la necesidad de conservar lo que con tanto esfuerzo han conseguido, dejando de lado tal vez un espíritu de solidaridad.

\subsubsection{Organización inicial}

La circunstancia de haberse instalado en un terreno pantanoso significó que los primeros momentos fueran muy duros, vividos en condiciones muy precarias, sobre todo por la insalubridad del terreno, aparte del temor que tenían de ser desalojados de un momento a otro. 
La peculiaridad del terreno supuso una organización inicial bastante peculiar destinada a superarla. Tardaron un año para empezar a rellenar. Durante ese tiempo no todos vivían en el terreno; estaban en casas de parientes y amigos, de donde iban a cuidar su terreno.

Más adelante veremos que los pobladores provenían en su mayoría de pueblos aledaños, lo que facilitaba el cuidado del terreno.

El Sr. Velásquez señaló al respecto:

"cuando uno invade, no vive inmediatamente, porque no está seguro si viene el desalojo [...] entonces pasaron por ese año para poder rellenar".

Para resolver los múltiples problemas iniciales se hacía necesario decisiones rápidas, por lo cual se organizaron en base a asambleas generales que se realizaban cada 24 horas.

El Sr. Velásquez nos cuenta que la invasión que se había hecho el 18 de diciembre era muy extensa. Entonces:

"[...] había algunas personas jóvenes que estaban preparadas, y ellos decían: bueno, ya vamos poniendo sector, sectorizando de esta parte más o menos, vamos a decir cien metros, un pueblito, de allí en adelante otro pueblo y ya de allí se ponen los nombres».

Es así como en un principio se diferencian los pueblos, independizándose cada cual y adquiriendo su propia organización de acuerdo a sus características particulares.

$Y$ así fue como dividieron lo que ahora es Sagrada Familia, Indonesia, Villa Municipal, Villa Mercedes (que fueron desalojados), Navidad de Villa, etc.

Respecto al nombre de "Sagrada Familia", se debió a la presencia de un padre que llegó a los dos días de la invasión y que los bautizó así.

\subsection{Características}

\subsubsection{Características de los pobladores}

\subsubsection{Origen y características demográficas}

De las encuestas y conversaciones efectuadas en el asentamiento humano Sagrada Familia podemos decir que su población está formada esencialmente por migrantes que antes de invadir este terreno no se conocían entre sí. 
Según se nos informó, su población proviene de otras zonas urbanomarginales como Campoy, Ciudad de Dios, Villa el Salvador y del asentamiento Delicias de Villa (Chorrillos), de donde proviene más del sesenta por ciento.

Es decir, no había ningún vínculo entre ellos anterior a la invasión, más que un interés común: la necesidad de vivienda. Ocuparon ese terreno porque ya los demás habían sido invadidos.

De los datos de la encuesta realizada podemos ver que hay una alta densidad demográfica, pues en cada lote habitan en promedio seis personas, habiendo encontrado hogares de hasta 12 personas.

En la mayoría de los casos son familias nucleares. Por lo general primero invadió una pareja con sus hijos y luego han pasado la voz a otros parientes o familiares, pero cada cual vive en su respectivo lote.

Otra característica de este pueblo es que se trata de una población joven. En cada hogar, sesenta por ciento, en promedio, son menores de edad, y de ellos el $80 \%$ asiste a algún colegio.

\subsubsection{Situación económica}

Otra de las características de los pobladores es su precaria situación económica. Tienen un nivel bajo de ingresos. Se presentan casos de pobreza extrema. No hay gran cantidad de desocupados; sin embargo, un porcentaje considerable se encuentra subempleado o se dedica a hacer cachuelos.

En cuanto a los que trabajan fuera de Chorrillos, la mayoría lo hace en condición de empleados u obreros.

No encontramos actividades económicas que proporcionen a sus habitantes posibilidades de empleo independiente, como podría ser en talleres, fábricas, etc. Salvo algunas pequeñas tiendas y un mercadillo, la actividad comercial no existe.

Sin embargo, como parte de una organización espontánea que surge del comedor popular, esporádicamente se crean talleres, como lo explicaremos en la parte pertinente.

\subsubsection{Fiesta comunal}

Un rasgo propio de este pueblo es que cada 18 de enero los pobladores de Sagrada Familia celebran su aniversario. En asamblea se nombra una comisión cuyo único fin será organizar la fiesta; en ella se realiza una actividad (pollada, rifa, etc.) en la que deben participar todos los pobladores, la cual es aprovechada para sacar fondos. El Sr. Velásquez nos comenta que para ellos es importante celebrar esta fiesta, porque: 
"ese día es en que se formó el pueblo; ese día nos conocimos todos y debemos celebrar el aniversario, como un cumpleaños».

\subsubsection{Organización}

\subsubsection{Dirigencia poblacional: un solo objetivo}

La organización comunal de Sagrada Familia cuenta con dos órganos: la junta directiva y la asamblea.

La asamblea está formada por los 170 socios y se reúne actualmente cada mes o cada dos meses para tratar asuntos concernientes a toda la población, aunque la asistencia a las asambleas ha disminuido según nos informan los dirigentes.

Esta asamblea es la que toma las decisiones, en principio, y puede ser convocada ordinaria o extraordinariamente en casos de urgencia. Se realiza en el local comunal con que cuentan en la parte central del asentamiento. Los estatutos contemplan una sanción en forma de multa, por inasistencia.

La junta directiva es la que representa al pueblo; se elige cada dos años, de acuerdo al estatuto que fue elaborado a los cuatro o cinco meses de la invasión.

La primera junta se eligió a los nueve días de la invasión y fue la que realizó las primeras acciones. Su objetivo era lotizar y rellenar todas las calles y conseguir luz y agua con carácter provisional.

La junta cuenta con los siguientes cargos según estatutos: secretario general, subsecretario general, secretario de actas, secretario de organización, tesorero, fiscal, dos vocales, secretario de prensa y propaganda, secretario de cultura y asistenta social.

Respecto a la elección, se realiza en asamblea, con propuestas de los asistentes y votación a mano alzada. Actualmente la junta directiva tiene un solo objetivo, como nos dice el subsecretario general, Sr. Velásquez:

"nuestro principal objetivo es el saneamiento físico-legal, porque teniendo eso nos faculta a tener, más fácil, préstamos o inversiones".

La población, por su parte, espera de la junta directiva que se encargue de obtener el título, como cuestión principal, y de hacer gestiones para conseguir los servicios, como cuestión secundaria o complementaria, según nos dijo un encuestado, el Sr. Nilo. 
Hasta hace unos dos años sus objetivos eran más amplios, pero al complicarse la situación del terreno fueron dejando de lado otras preocupaciones para dedicarse únicamente a las gestiones relacionadas con éste.

Entre otras cosas, nos comentaron que antes tenían rondas para protegerse de la delincuencia debido a la falta de protección policial, sobre todo por los frecuentes robos. Al respecto consideran que a un ladrón se le puede perdonar una vez, pero si reincide se le debe dar una buena paliza, «un buen golpe».

Otras actividades que han dejado de la lado son las culturales y deportivas, que antes se llevaban a cabo. La junta ha dejado de lado todo por resolver su principal problema: el saneamiento fisico-legal del terreno, y por eso todos los fondos que se obtienen actualmente se destinan a gastos administrativos, como los provenientes de multas y cuotas administrativas. De sus gastos administrativos destinan una cantidad para abogados.

Este problema de la propiedad del terreno, el cual en un inicio creían era del Estado y luego se ha complicado con la aparición de un dueño, ha obligado a los dirigentes a compenetrarse con el mundo legal, lo que es ajeno para los pobladores.

Actualmente la junta directiva se encuentra totalmente avocada a gestiones ante el INRENA y la Municipalidad de Lima, además del juicio con el supuesto dueño del terreno.

\subsubsection{Organizaciones sociales de base}

Aparte de la organización central de la junta directiva y las asambleas, y como una respuesta a las necesidades más elementales de la población, se han formado dos tipos de organizaciones sociales de base: comedores populares y comités de vaso de leche, que son independientes, en su funcionamiento y organización, de la junta directiva.

Existen dos comedores en todo el asentamiento humano: el parroquial y el del club de madres. Ambos comedores tratan de cubrir las necesidades alimenticias, enfrentándose con muchos problemas.

Por ejemplo: el comedor del club de madres no cuenta con ayuda; sólo una provisional de PRONAA, ya que no cumplen con el requisito numérico que otras entidades exigen.

Pero lo más importante es el rol de la mujer, porque es ella la principal propulsora de estos comedores. El comedor popular tiene 30 socias activas que cocinan un promedio de 100 menúes diarios, enfrentándose creativamente a la crisis y superando los obstáculos (como la falta de agua para cocinar). 
Existe un solo comité del vaso de leche en todo el asentamiento humano, destinado principalmente a los niños.

En estas organizaciones sociales de base resalta un sentido de solidaridad, pues además de servir a sus miembros están siempre dispuestos a dar ayuda a personas necesitadas.

La Sra. Teresa (presidenta del comedor del club de madres), nos dice:

"[...] damos ayuda a dos personas y a un niño huérfano; a esas personas les damos porque son ancianas. Antes dábamos también a madres solteras pero hemos visto en una reunión que ellas pueden trabajar, beneficiarse recibiendo cinco menús gratis, porque, si no, se acostumbran".

No toda la población se beneficia de estas organizaciones. Para el comedor, quienes desean menú deben inscribirse diariamente, y para el vaso de leche deben pagar semanalmente para beneficiarse.

\subsubsection{Organización espontánea}

Ante la incapacidad de la junta directiva para satisfacer las necesidades del pueblo, debido a su obsesión por lograr el saneamiento físico-legal, que le ha hecho perder de vista otros aspectos también importantes, surge una organización espontánea. Esta organización espontánea surge tanto del pueblo como de los comedores, en especial del comedor del club de madres. Y son otra vez las mujeres las que se ocupan de ello. Ante la presencia de algún problema grave, y en vista de que no hay asistenta social (el cargo existe en la junta, pero en realidad no funciona), las mujeres se organizan para pedir una colaboración y ayudar a la persona afectada.

En caso de accidentes o fallecimientos, todos los vecinos y conocidos de la persona afectada se unen para colaborar con ella. Alguien se ofrece y se encarga de pedir colaboración, por ejemplo, para el traslado del accidentado al hospital, ya que en todo el pueblo no existe ni siquiera un botiquín de primeros auxilios.

Al respecto, los miembros de la junta son conscientes de esa necesidad, pero consideran que el dinero que es para trámites administrativos no puede ser utilizado para otra cosa.

Esta organización espontánea es temporal, surge sólo por un suceso especial y muchas veces significa sólo una solución parcial, por la limitación de recursos de las personas, que quisieran ayudar más pero no cuentan con medios para hacerlo.

Por otro lado, la Sra. Teresa (presidenta del comedor del club de madres y personaje del pueblo No 16) nos comentaba que para Navidad 
iban a tratar de formar un taller en donde hacer muñecos para sus niños y para que sirviera a las madres como una pequeña ayuda.

\subsubsection{Relación con otros grupos sociales}

El asentamiento humano Sagrada Familia se encuentra ubicado en el sector marginal de Villa-Chorrillos y las relaciones que entabla con los pueblos colindantes son para satisfacer necesidades, utilizando servicios con los que ellos no cuentan.

Con Las Delicias de Villa mantienen una relación de dependencia en cuanto a los servicios de salud, ya que al ser aquélla un pueblo de casi cuarenta años, cuenta con una posta médica que, si bien es pequeña, es la única para todo ese sector.

Además, en Las Delicias está el local donde recogen la leche para luego llevarla al local del comité, y se encuentra también la parroquia Jesús Obrero, a la que asisten.

De otro lado, con los Huertos de Villa, colindante por el lado oeste, mantienen una relación de cooperación ya que firmaron un acuerdo por el cual los Huertos de Villa les tendieron una instalación para el único pilón de agua con que cuentan.

Cabe agregar que cuando las madres gestantes están por dar a luz acuden al hospital María Auxiliadora de San Juan de Miraflores o a la maternidad -muy lejos del asentamiento-, pues no hay ningún hospital cercano que pueda atenderlas.

Con los pueblos aledaños, cercanos a los pantanos, Sagrada Familia se comprometió a realizar un esfuerzo conjunto para coordinar con SEDAPAL la realización de un proyecto integral de agua y desagüe que evite la contaminación de los pantanos. (Los dirigentes nos manifestaron que esto es una prueba más de que ellos sí se preocupan por la ecología.)

No hay ninguna confederación de asentamientos. Cada uno hace sus gestiones por su lado, a veces con ayuda de la municipalidad.

\subsection{Dualidad de concepciones: pobladores y junta directiva}

De las entrevistas realizadas se desprende que la junta directiva se encuentra alejada de la población; ya no hay confianza; su poder se encuentra deslegitimado.

Ya nadie quiere pagar las cuotas y multas administrativas, pues no hay resultados concretos sobre la situación del terreno. 
Este alejamiento se refleja en la propia concepción de los dirigentes, quienes piensan que no deben intervenir en los problemas de los pobladores. Consideran que cada uno debe resolverlos y salir adelante como mejor pueda; ellos sólo se ocupan de la parte formal del terreno. La concepción de los pobladores, por el contrario, es de ayuda mutua.

De otro lado, encontramos una diferencia muy interesante en lo que piensan los pobladores respecto de la junta directiva, dependiendo de si son hombres o mujeres.

La junta directiva dice que si bien hay problemas éstos se están solucionando y no hay nada que temer, y curiosamente los varones entrevistados opinan algo similar.

En cambio, las mujeres mostraron una total desconfianza hacia la junta. La Sra. Delia, vendedora de pollo, nos dijo que:

«sólo sirven para sacar dinero y no han hecho nada. Cualquier día de estos nos van a [...] botar, por eso la gente no da plata».

Estas diferencias pueden explicarse porque son los hombres los que participan en las asambleas y en la junta directiva, ya que éstas se realizan de noche, y las mujeres se quedan en casa ocupándose de las labores y cuidando a los niños.

Las mujeres consideran muy difícil que se arregle el problema; no confían en las gestiones de la junta directiva, a la que además consideran insensible, pues si alguien no puede pagar las cuotas no lo ponen en el padrón; no les importa nada.

Ante la indiferencia de la junta respecto de los problemas concretos de la población, las mujeres se organizan para ayudarse a través de los comedores populares.

Son ellas las que se preocupan de los más pobres. La Sra. Inés, vendedora ambulante de verduras, nos dijo que:

«los más pobres siempre asisten a los trabajos comunales; los otros, ni van ni pagan sus multas».

\section{La tenencia de la tierra en el asentamiento humano Sagrada Familia}

\subsection{Distribución de la tierra}

Cuando recién se inició la invasión, las familias se acomodaron provisionalmente en forma desordenada, con lo cual no hubo un criterio de 
distribución. Fue después cuando la junta directiva empezó la lotización.

La junta directiva tomó en cuenta los siguientes criterios, para repartir los lotes, en forma preferencial: asistencia a las asambleas, mayor participación en trabajos comunales; mayor colaboración, en general.

Los lotes preferenciales eran los ubicados frente a las vías centrales: Panamericana Sur y avenida Doce de Octubre, los cuales se repartieron de acuerdo a los criterios señalados.

La distribución de la tierra se hizo en base a criterios comunales de trabajo y/o aporte dinerario. Existía un sistema de cuota fija para quienes tenían trabajo estable; quienes no lo tenían, o eran de menores recursos, daban un aporte voluntario o participaban en los trabajos comunales.

Los trabajos comunales consistían en juntar la basura, limpiar el campo deportivo; además, rellenar las zonas comunes como parques, pistas, entre otros, lo cual era obligatorio para todo poblador. De lo contrario, se imponía una multa.

Sin embargo, solía ocurrir, según nos narran algunos, que:

«los más pobres siempre asisten a los trabajos comunales; los otros ni van ni pagan sus multas».

La distribución de la tierra por la junta directiva se basó en un criterio calificado, nos expresó el Sr. Velásquez (subsecretario general), quien al respecto señala:

«los moradores tampoco van a venir a imponerse, porque si ellos han venido con el propósito de tener un terreno donde vivir, entonces automáticamente de una asamblea tiene que salir eso, se crea un consenso; y si a la vez era calificado, persona que venía permanentemente y colaboraba, tenía la mayor prioridad de ir a un lugar mejor".

La lotización no se realiza de inmediato, pues hay la necesidad de organizar al pueblo primero; además no hay seguridad y hay un constante miedo al desalojo; por ello, luego de un año recién comienzan a rellenar y luego a distribuir la tierra.

Sagrada Familia se lotizó en 170 lotes para igual número de asociados. Tomando en cuenta un promedio de dos familias por lote, su población es de aproximadamente 340 familias. 


\subsection{Sistemas de tenencia de la tierra}

En este rubro podremos observar las particularidades surgidas por la necesidad de enfrentar una situación real (la invasión de un pantano) y la creatividad de los pobladores para ello.

\subsubsection{Sistema de relleno}

Ya que el terreno invadido era imposible de urbanizar en sus condiciones normales, era fundamental rellenar la zona pantanosa hasta crear una superficie estable.

Podemos dividir este sistema en dos tipos:

a) Relleno individual.- Cada familia rellenaba el espacio correspondiente a su lote. Según sus posibilidades económicas podían pagar volquetes para que les facilitaran esta tarea. Acá no había ayuda entre las familias; el relleno del lote individual dependía de cada familia y si no tenían posibilidades demorarían más tiempo en rellenar.

De lo anterior se deriva un peculiar derecho que los pobladores sienten sobre el relleno de su lote, al cual hemos denominado "derecho de relleno». Cada familia se siente propietaria de su relleno pues ha sido fruto de su esfuerzo y trabajo.

Un poblador expresó indignado que:

"ino es posible!, nosotros hemos trabajado, nos hemos esforzado y ahora que el terreno ya ésta arregladito viene un dueño a reclamarlo".

De aquella respuesta se denota el derecho que sienten tener los pobladores básicamente en función de su esfuerzo y trabajo.

b) Relleno comunal. - Lo primordial para la junta era el relleno de las calles, para lo cual todos tenían que colaborar y coordinar. En este caso sí existía un sentido de cooperación. Los vecinos cuyos lotes quedaban frente a frente debían coordinar para rellenar su calle.

Había zonas públicas como parques, el local para las asambleas, etc., las cuales debían ser rellenados también por los vecinos.

\subsubsection{Superficie}

$\mathrm{Al}$ respecto, los pobladores consideran que el terreno le corresponde en propiedad a la junta directiva, que es la encargada de distribuir los lotes 
y de ver las transferencias y todo asunto relacionado con la tenencia de la tierra.

Sin embargo, existe una situación difícil, porque los pobladores asumen que la junta directiva es propietaria del terreno, sin dejar de reconocer que el Estado también tendría derecho al ser el terreno invadido una zona ecológica. Además, existe un tercero particular que también reclama la propiedad.

El problema se puede apreciar de palabras de un poblador:

"Veo difícil la situación, puede ser que nos boten. Hay tres dueños».

Siendo la junta directiva la encargada de distribuir los lotes, ésta le asignó a cada familia un área de la superficie total.

Los pobladores no se sienten propietarios de la superficie de su lote; a pesar de ello han rellenado su lote y han construido sobre él y sienten que nadie puede invadir su terreno después que la junta les ha asignado el lote y los ha inscrito en el padrón. Lo que sucede, como luego se analizará, es que ellos no diferencian entre propiedad y posesión.

La junta directiva lleva un padrón donde se inscribe el lote correspondiente a cada poblador y es éste el que asegura el derecho; es por ello que cuando se transfiere el lote debe darse aviso a la junta para inscribir a la nueva familia; de lo contrario ella no le reconocerá ningún derecho.

\subsubsection{Vivienda}

Los pobladores se sienten propietarios de su vivienda, ya que cada uno la ha edificado con sus propios recursos.

Debido a que la mayoría de viviendas son de esteras, maderas, $\mathbf{u}$ otros materiales que son trasladables, cuando una familia se muda generalmente lleva consigo todas sus cosas, llevando prácticamente «su casa a cuestas".

En los pocos casos en que las viviendas son de material noble, también se reconocen propietarios, lo que se refleja en que no transfieren sus casas, cosa que por lo demás sería extraña, pues si con tanto esfuerzo un poblador llegara a construir de concreto su casa, sería para quedarse definitivamente alli. 


\subsubsection{Zonas públicas}

Como ya adelantáramos al hablar del relleno, existen zonas comunes. Estas zonas, como las calles, el parque, el terreno para asambleas, el comedor, la parroquia, etc., son zonas respecto de las cuales los pobladores no sienten un derecho individual, sino que consideran que, al igual que el lote que poseen, estas zonas son de propiedad de la junta directiva.

Sin embargo, ellos tienen un derecho común sobre ellas; a diferencia del derecho particular que tienen respecto de su lote, son áreas comunes que benefician a todo el asentamiento humano, sin que nadie tenga un derecho particular sobre ellas.

\subsubsection{Transferencia de terrenos}

Si un poblador desea transferir su lote a un tercero, debe comunicarlo a la junta directiva. Ésta inscribe en el padrón a la nueva familia, sin lo cual no se le reconocerá ningún derecho.

La junta directiva reconoce el "derecho de relleno", pues cuando alguien desea mudarse la junta le reconoce los gastos ocasionados por el relleno, pasando dicho terreno a la junta para que lo adjudique a otra familia, la que deberá a su vez pagar el «derecho de relleno». De igual modo, cuando una familia desea transferir su lote a otra familia ésta debe reconocer el "derecho de relleno" al transferente.

\subsection{Visión de los pobladores}

En este punto es interesante contrastar la opinión que tienen los pobladores con la que tiene la junta directiva.

Para el Sr. Velásquez no hay peligro de que los pobladores de este asentamiento humano pierdan los derechos que actualmente tienen sobre el terreno invadido. Nos explicó que la junta ha llegado a un acuerdo con el INRENA por el cual los pobladores no serán desalojados si es que se encargan de custodiar la zona que aún permanece pantanosa e impiden que otras personas puedan invadir estas áreas. Lo único que importa ahora-según él-es el saneamiento físico-legal, es decir:

"que todos los papeles queden en regla».

Los pobladores no comparten esta perspectiva; todo lo contrario, experimentan inseguridad y no pueden sentirse propietarios reales del terreno que ocupan. Existe desconfianza. 
Ellos piensan que otra persona podría reclamar el terreno, lo cual no les parece justo, pues, en cierta forma, el trabajo invertido para convertir el pantano en una zona habitable les concede un mayor derecho a quedarse con el terreno.

Ante un posible proceso judicial con el tercero que reclama la propiedad del terreno, tienen una actitud escéptica. En su opinión, los jueces no les reconocerán el trabajo realizado. Un poblador señaló al respecto:

"los juicios los ganan los que tienen plata".

De sus palabras puede extraerse el concepto de justicia que predomina entre los pobladores. Los pobladores tienen una visión lejana de lo que es el Derecho oficial; no saben si tienen derecho acorde a las reglas oficiales. Algún poblador señaló:

"¿Qué dirá, el derecho? Nosotros podemos decir que tenemos derecho, pero vienen los abogados y dicen otra cosa, y qué podemos hacern.

Por otro lado, su visión respecto al gobierno central tampoco fue muy positiva. Algunas de sus respuestas fueron:

«No creo que pueda haber ayuda del gobierno; por aquí no llegan». "El gobierno, en los pueblos jóvenes sólo se preocupa de los colegios». "Los alcaldes, para entrar sí vienen; luego no cumplen".

\section{Análisis comparativo de la institución de la tenencia de la tierra con el Derecho civil}

Luego de presentados los aspectos característicos del asentamiento humano Sagrada Familia, y habiendo destacado el papel relevante de la tenencia de la tierra en la vida de sus pobladores, nos toca ahora señalar el conjunto normativo encargado de regular, directa o indirectamente, la actual situación de este asentamiento humano.

De esta manera, lograremos no sólo determinar con precisión aquellas circunscancias reguladas legalmente o no, sino también facilitar el camino hacia una o varias posibles respuestas a sus necesidades. 


\subsection{Normatividad vigente}

\subsubsection{Pantanos de Villa}

Entre las normas protectoras de este centro ecológico tenemos la resolución ministerial 00144-89-AG/DGFF (29.5.89), que prohíbe la caza de animales silvestres, la extracción de flora y fauna y otras actividades de explotación de recursos naturales renovables, en un afán de conservación de esta área ecológica, declarándola zona reservada.

Esta resolución encarga al patronato de defensa de los Pantanos de Villa el área reservada, quedando la Dirección General de Forestal y Fauna y la Unidad Agraria Departamental VI-Lima, encargadas del cumplimiento de lo antes expuesto.

En la práctica el peligro continuaba, por lo cual se da el decreto supremo 007-91-PCM (9.1.91), encargando al Ministerio de Defensa el resguardo de los Pantanos de Villa y quedando imposibilitado de ceder el uso total o parcial del área a terceros.

Otras normas específicas sobre el tema son el acuerdo de concejo 026 (31.1.92) y el decreto de alcaldía 110 (1.7.92). El primero declara al parque metropolitano de Villa, zona donde se hallan los pantanos, como área ecológica metropolitana, y a través del segundo se establecen sanciones a quienes viertan aguas contaminadas o desechos tóxicos en el lugar, pudiendo esta sanción administrativa (consistente en una multa) originar una denuncia penal. La Municipalidad de Lima delega la facultad de sancionar, y de limpiar el área, a su similar de Chorrillos.

Finalmente, como norma general tenemos el Código del Medio Ambiente y los Recursos Naturales (decreto legislativo 611) (8.9.90), modificado luego por el decreto legislativo 708 (14.11.91). Este código contiene disposiciones interesantes, como los artículos 4,5 y 7 , sobre planificación ambiental, donde el artículo 5 dice a la letra:

«Art. 5.- La planificación ambiental comprende el ordenamiento del territorio, de los asentamientos humanos y de los recursos para permitir una utilización adecuada del medio ambiente a fin de promover el desarrollo económico sostenido."

Asimismo, se desarrolla todo un capítulo, De la Población y el Ambiente, a través del cual se busca una adecuada política poblacional y de acción conjunta entre el gobierno y los habitantes. 


\subsubsection{Asentamientos humanos}

Citaremos los dispositivos más importantes para los fines de este trabajo. Para empezar, tenemos la ley 13517, ley orgánica de Barrios Marginales (14.2.61). Esta norma es muy significativa dado que es la primera que regula asentamientos humanos y define por primera vez lo que es un barrio marginal (primer nombre legal que tuvieron los asentamientos humanos) en su artículo 4 , inciso a:

«Art. 4.- Para los fines y aplicaciones de esta ley se considera:

a) "Barrio Marginal" o "Barriada», la zona de terreno de propiedad fiscal, municipal comunal o privada que se encuentre dentro de los límites de centros poblados, capitales de circunscripción político-administrativa, o en sus respectivas áreas suburbanas o aledañas, en las que, por invasión al margen de las disposiciones legales sobre propiedad, con autorización municipal o sin ella, sobre lotes distribuidos sin planes de trazado oficialmente aprobados, se hayan constituido agrupamientos de viviendas de cualquier estructura, careciendo dicha zona en conjunto de uno o más de los siguientes servicios: agua potable, desagüe, alumbrado, veredas, vías de tránsito vehicular, etc. [...].»

La ley, además de buscar el crecimiento ordenado de las barriadas y el reconocimiento de las mismas, también busca evitar la creación de nuevas barriadas. Esto se deduce del artículo 2, donde excluye de los alcances de la norma a las barriadas formadas luego del 20.9.60, y prohíbe el establecimiento de las mismas.

Otro dispositivo es la ley 23853, ley orgánica de Municipalidades, la cual encarga a los municipios asistir a los pobladores de los asentamientos humanos de su jurisdicción para el saneamiento físico-legal y la titulación, la que será conferida por el concejo provincial.

Esta norma es la primera en usar el término «asentamientos humanos" (y no "barrios marginales", "barriadas" o "pueblos jóvenes" o "asentamientos humanos marginales»).

También tenemos el reglamento de Saneamiento Físico-Legal de los Asentamientos Humanos (decreto supremo 053-84-VC). La propia norma define al saneamiento como el establecimiento, regularización y ejecución de un plano urbano donde se haya previsto el trazado, lotización, áreas de uso público, vías, etc., mientras que el saneamiento legal está orientado a la entrega en propiedad del lote de cada familia. 
Este reglamento ha sido sustituido por el decreto de alcaldía 107-A (25.7.91). Este nuevo reglamento describe el proceso de saneamiento de un asentamiento humano, el cual consta de las siguientes etapas:

a) Identificación y calificación.- El municipio distrital reconoce a un determinado grupo de pobladores como asentamiento humano y lo califica como permanente o erradicable total o parcial.

b) Aprobación del plano perimétrico- La municipalidad, previo estudio de la situación jurídica del terreno, señala cuáles son sus límites y el área que comprende.

c) Aprobación del plano de lotización.- Esta etapa tiene dos manifestaciones, según sea el caso. Si el asentamiento humano solicita al municipio aceptar el proyecto de trazado y lotización antes de su ejecución, entonces estaremos ante la aprobación de un anteproyecto de trazado y lotización. Sin embargo, puede ser que este asentamiento ya haya ejecutado este anteproyecto o haya lotizado y/o remodelado sin solicitud previa de aprobación al municipio; en estos casos los pobladores pedirán la aprobación del plano definitivo de trazado y lotización.

En este momento es donde se determina el ordenamiento urbano en general: número de lotes, área de los mismos, vías de acceso, usos del terreno, etc.

d) Empadronamiento y titulación.- En esta etapa se registran los datos de la persona o familia ocupante del lote, así como toda la información necesaria. Luego de este empadronamiento y de seleccionar las familias que cumplan con los requisitos, el municipio distrital eleva la información al concejo provincial para que, a través del SERMIN (Empresa de Servicios de Informática), emita los títulos de propiedad, remitiendo copia a los registros donde se encuentren inscritos el plano perimétrico y definitivo del trazado y lotización del asentamiento humano.

La ley 24513 (3.6.86) ordena que el proceso de saneamiento hasta la aprobación del plano de lotización deberá durar como máximo 120 días de plazo, vencido el cual los expedientes pasarán al Ministerio de Vivienda y Construcción. Esto motivó una reacción tal, que la ley fue cuestionada y dejada en el olvido.

Finalmente tenemos la ley 25102 (3.10.89), la cual amplía los alcances de la ley 24513, pero destaca por cuanto retoma el término "pueblo joven", aunque leyes posteriores dejaron de lado este nombre por el de "asentamientos humanos". Posteriormente fue dado el decreto supremo 016-89-VC (6.12.89), el cual reglamenta la ley 25102.

Otra norma al respecto es el decreto supremo 019-87-VC, el cual establece requisitos para adquirir lotes de vivienda en pueblos jóvenes. 


\subsubsection{Código Civil}

Para el presente trabajo nos serán útiles todas las disposiciones referidas a los derechos reales de propiedad, posesión y superficie.

En lo que respecta a la propiedad tenemos el artículo 923, el cual describe este derecho como un "poder jurídico que permite usar, disfrutar, disponer y reivindicar un bien», debiendo ejercerse en armonía con el interés social.

Hay otros tres artículos relevantes sobre propiedad. En primer lugar, el artículo 954 nos señala los límites de la propiedad de un predio, la que se ejercerá tanto en el subsuelo y sobresuelo comprendidos dentro de los planos verticales del perímetro superficial, no comprendiendo los recursos naturales, los yacimientos y restos arqueológicos, ni otros bienes regidos por leyes específicas.

Vale decir, el derecho de propiedad no se limita a la superficie, sino que se extiende a todo lo que se halle sobre y bajo ésta dentro de los linderos del predio. Este derecho tiene un límite: la utilidad que tenga para el propietario su ejercicio.

En segundo lugar, el artículo 955 permite que el subsuelo o el sobresuelo, en principio de un mismo propietario según lo expuesto anteriormente, pertenezca total o parcialmente a persona distinta del propietario del suelo. De esto se infiere que sólo el dueño del suelo tiene la facultad de ceder el subsuelo, sobresuelo o ambos, aunque no lo especifique la norma.

Por último, el artículo 957 nos indica que la propiedad predial queda sujeta a la zonificación, a los procesos de habilitación y subdivisión y a otros establecidos por las normas respectivas.

Por otro lado tenemos la copropiedad, un régimen especial de propiedad. Este derecho consiste en la pertenencia de un bien a dos o más personas, la cual no se concretiza en cuotas materiales, es decir, dividiendo el bien, sino en cuotas alícuotas o ideales, las cuales se presumen iguales según el artículo 970. Estas cuotas son las que determinan la participación del propietario tanto en los beneficios como en las cargas que tengan origen en la propiedad del bien, así como el valor de los votos en la toma de decisiones, ya sea por mayoría (actos de administración ordinaria) o por unanimidad (en caso de disposición, gravamen, arrendamiento, entrega en comodato o modificación del bien).

La copropiedad también da derecho a asumir la administración y emprender los trabajos para la explotación normal del bien, pero siempre y cuando no haya administración convencional o judicial (art. 973). Si la cuota ideal se concretiza, es decir, se divide o parte el bien, la copropiedad fenece (art. 922, inc.1). 
De lo antes dicho se desprenden varios deberes de los copropietarios, como no usar el bien parcial o totalmente con exclusión de los demás (art. 975), concurrir proporcionalmente en los gastos de conservación y en el pago de tributos, cargas y gravámenes que afecten al bien (art. 981), entre otros.

En cuanto a los derechos, el copropietario puede servirse del bien común siempre que no afecte el interés de los demás (art. 974), disfrutar del mismo (art. 976), disponer de su cuota ideal y de los frutos de ésta (art. 977), y puede reivindicar el bien (art. 979).

Finalmente, en lo que toca al derecho de superficie (una persona llamada superficiario puede construir sobre un suelo que puede o no ser de su propiedad), el Código Civil señala que no puede durar mas de noventa y nueve años (art. 1030); su constitución se da por acto entre vivos o testamento, siendo el derecho transmisible (art. 1031); no se extingue por la destrucción de lo construido (art. 1033), por citar lo más importante.

\subsection{Análisis comparativo: Derecho y realidad}

Habiendo citado en el punto anterior las disposiciones legales destinadas a regular el tema, pasaremos a compararlas con la realidad observada en el asentamiento humano, poniendo énfasis en la institución que hemos denominado "derecho de relleno".

\subsubsection{El derecho de relleno y la ley}

\subsubsection{Derecho de propiedad y posesión}

A manera de recapitulación, el "derecho de relleno" consiste en que el poblador de cada lote del asentamiento humano se siente dueño del espacio comprendido entre el suelo pantanoso y la superficie donde construyó su vivienda, dado que fue él mismo quien cubrió esa zona del pantano para poder instalarse.

De este modo, el habitante considera que el suelo es del Estado y de la junta directiva (confusión entre derecho y propiedad), y que el relleno y la vivienda le pertenecen.

Incluso, aunque el asentamiento humano reconoce al Estado como propietario de esta zona reservada, le reconoce también derecho a un tercero que actualmente litiga con el Estado esta área; es decir, en su 
forma de pensar ellos admiten la existencia de tres dueños: el Estado, el tercero y la junta directiva en representación del asentamiento humano.

Un intento de explicación de esta figura consistiría en equipararla con la propiedad. El poblador está convencido de que ese relleno y esa vivienda son suyas y nadie podrá quitárselos, lo que no ocurre con la superficie; es por esto que se siente con derecho a ejercer los atributos de la propiedad sobre aquéllos, como por ejemplo, transferirlos a un tercero.

Asimismo, no habría contradicción aparente con el artículo 955 sobre propiedad predial, donde se permite a un tercero ser propietario del subsuelo o sobresuelo habiendo un propietario del suelo.

Sin embargo, el problema no es de tan simple solución. Puede pensarse que los pobladores, al decir que la junta es la dueña de la tierra y quien la reparte, manifiestan que el terreno es de ellos como pobladores, porque saben también que esta junta directiva es quien los representa y no la consideran una entidad exterior a ellos.

$\mathrm{Si}$ es así, ellos se estarían reconociendo como dueños del relleno y la vivienda como propiedad individual, y de la superficie en forma comunal. Empero, no puede hablarse de propiedad desde que están asentados en un lugar que, como la Constitución en su artículo 73, y ellos mismos, admiten, pertenece al Estado y es un bien de dominio público inalienable e imprescriptible.

En todo caso, el Estado está dispuesto a reconocerlos y darles la titulación de ese territorio a través del Concejo Provincial de Lima, siempre y cuando cumplan con las etapas y plazos señalados en el decreto de alcaldía 107-A, según la resolución 1845 donde Sagrada Familia es identificada como asentamiento humano.

Por último, cabe resaltar que ellos no distinguen entre los conceptos de propiedad y posesión, sino que los identifican: dentro de su concepción ellos son propietarios, pero si la ley señala a otro u otros como tales, entonces esta propiedad desaparecería, pues el derecho de propiedad es único.

La posesión es otra figura legal con la cual nuestro "derecho de rellenow tiene cosas en común. Aunque los pobladores hablan de una propiedad, se están refiriendo a una posesión en tanto usan y disfrutan del terreno hasta que obtengan los títulos o hasta que un tercero al amparo de la ley los desaloje; sin embargo, jamás podrían ganar el terreno por prescripción por orden de nuestra Constitución. No obstante, esta posesión, en principio ilegítima, empieza a enmarcarse en la ley al ser reconocido el asentamiento humano por la resolución 1845 del 17 de agosto de 1990 y, por ende, al iniciar el proceso de saneamiento físico-legal. 


\subsubsection{Derecho de superficie}

Otra figura legal similar a este derecho es el derecho real de superficie. Los pobladores serían superficiarios de los lotes que les otorga la junta directiva, pudiendo construir sobre ellos y teniendo en propiedad esa construcción. Vale la pena destacar el trabajo organizado de los vecinos para rellenar lo que serían sus calles, etc., por lo cual todos los participantes en esta actividad se sienten con derecho al relleno. Esto chocaría de algún modo con la ley, ya que las calles son de uso público y nadie puede detentar propiedad sobre ellas.

Sin embargo, los diferencia el hecho de que el superficiario debe recibir el lote del propietario del suelo, y en el caso de Sagrada Familia la junta directiva, aunque considerada como la dueña del suelo, no puede darlo en superficie porque legalmente no hay propiedad sobre esta tierra. Por otro lado, el derecho real de superficie tiene una duración de noventa y nueve años; en cambio, el poblador siempre será dueño de su relleno y de su vivienda.

\subsubsection{Derecho de copropiedad}

Anteriormente dejamos sentado que los pobladores de Sagrada Familia se sentían dueños comunales del terreno, cuya administración encargaban a la junta directiva. Esto desde un primer momento nos sugiere la existencia, entonces, de una copropiedad del terreno, y del relleno correspondiente a las zonas públicas, calles, parques, etc. En el primer caso, la tenencia de la tierra en Sagrada Familia no encajaría dentro del modelo de copropiedad, puesto que no existen cuotas alícuotas, sino partes concretas del bien ya entregadas a los pobladores y/o familias del asentamiento humano.

De todo lo antes dicho se desprende que el derecho de relleno es una institución sui generis, en tanto surge de una realidad específica que la normatividad en general (leyes, Código Civil) no ha regulado.

$\mathrm{Al}$ no encajar perfectamente en ninguna de las instituciones legales, nuestro derecho de relleno se presenta como una salida original, por decir lo menos, al problema que implica el no sentirse seguros de la propiedad del suelo donde se habita; y constituye además un intento de explicación coherente de la situación de la tierra, que los pobladores reconocen como del Estado y de Sagrada Familia. 


\section{Conclusiones}

\subsection{El asentamiento humano Sagrada Familia}

1. La junta directiva, debido al problema del terreno, se ha trazado un único objetivo: el saneamiento físico-legal.

2. Debido a que no se pueden palpar resultados concretos sobre la solución del problema de la tierra, la junta directiva va perdiendo credibilidad.

3. Las organizaciones sociales de base ayudan a satisfacer las necesidades básicas de alimentación, que son dejadas de lado por la junta directiva.

4. Las organizaciones sociales de base tienen el apoyo de la población, y son el canal de solución espontánea de problemas no resueltos por la junta directiva.

5. Las organizaciones sociales de base se fundan en un sentido de solidaridad.

6. El asentamiento humano Sagrada Familia depende de otros pueblos respecto de las necesidades que no puede satisfacer.

7. La junta directiva confía en poder resolver el problema.

8. Los pobladores desconfían de la capacidad de la junta para solucionar los problemas.

\subsection{La tenencia de la tierra en el asentamiento humano Sagrada Familia}

1. La distribución de la tierra se basó en los siguientes criterios:

- Asistencia a asambleas.

- Trabajos comunales (limpieza de parque, recojo de basura).

- Colaboración y participación.

2. Se determinaron vías centrales preferenciales para la distribución, que fueron:

- Antigua Panamericana Sur.

- Avenida Doce de Octubre.

3. Se dieron dos clases de relleno:

- Relleno individual: cada familia rellenaba su lote. 
- Relleno colectivo: las familias cuyos lotes estaban frente a frente debían rellenar la calle que los unía.

4. Los pobladores consideran a la junta dueña del terreno; sin embargo, siendo ésta representante del pueblo, podemos considerar que se trata de un terreno comunal. Por otro lado, reconocen que el Estado también tiene derecho.

5. La junta otorga un área de superficie, un lote a cada familia.

6. Cada familia tiene derecho para rellenar y construir en ese lote siempre que se encuentre inscrita en el registro que posee la junta.

7. El registro que posee la junta, en consecuencia, es constitutivo de derecho.

8. Cada familia se siente propietaria de su relleno en base a un criterio de trabajo y esfuerzo.

9. Cada familia tiene derecho de propiedad sobre su casa.

10. Las zonas públicas son áreas comunes de las cuales todos se benefician. Éstas no se independizan del terreno general, sino que como parte de éste pertenecen a todos.

11. La transferencia de un lote se hace a través de la junta, la cual reconoce el «derecho de relleno".

12. No se reconoce derecho sobre el lote, el cual debe retornar a la junta para que lo otorgue a otra persona.

13. Los pobladores no esperan apoyo del gobierno.

14. Existe un desconocimiento sobre el Derecho oficial.

15. Algunos pobladores consideran que los juicios los ganan quienes tienen plata.

\subsection{Análisis comparativo de la institución de la tenencia de la tierra con el Derecho civil}

1. Los pobladores tienen un derecho de propiedad sobre el relleno y sobre sus viviendas.

2. Los pobladores reconocen la existencia de varios dueños, lo cual se contradice con el Derecho.

3. Existe un conflicto jurídico respecto a la propiedad del terreno. Pero los pobladores no podrían adquirir el terreno por prescripción, pues los bienes del Estado no son susceptibles de ello.

4. La junta otorga un derecho sobre la superficie de un lote para que una familia pueda construir sobre el suelo o sobresuelo.

5. Sin embargo, no se trata de un derecho de superficie por cuanto 
éste es otorgado únicamente por el propietario, y la junta legalmente no lo es.

6. Por otro lado, la ley establece un plazo de noventa y nueve años al derecho de superficie, luego del cual lo construido pasa a poder del propietario, lo que no sucede con el relleno ni la vivienda.

7. Los pobladores, por representación de su junta directiva, parecerían ser copropietarios de todo el terreno. Sin embargo, el modelo de copropiedad tampoco encaja, pues no hay partes alícuotas sino que ya se ha dado un lote específico a cada trabajador, y ni siquiera en propiedad.

8. Al no encajar con precisión en ninguna de las instituciones reales, el "derecho de relleno" constituye una salida original para explicar la situación de la tierra que los pobladores reconocen como del Estado y de la junta directiva en su representación. 